\title{
Implementing Interorganizational Cooperation in Labour Market Reintegration: A Case Study
}

Christian Ståhl

The self-archived postprint version of this journal article is available at Linköping University Institutional Repository (DiVA):

http:/ / urn.kb.se/ resolve?urn=urn:nbn:se:liu:diva- 71701

N.B.: When citing this work, cite the original publication.

The original publication is available at www.springerlink.com:

Ståhl, C., (2012), Implementing Interorganizational Cooperation in Labour Market Reintegration: A Case Study, J ournal of occupational rehabilitation, 22(2), 209-219. https:// doi.org/ 10.1007/ s10926-011-9337-x

Original publication available at:

https:// doi.org/ 10.1007/ s10926-011-9337-x

Copyright: Springer Verlag (Germany)

http:/ / www.springerlink.com/ ?MUD=MP 


\title{
Implementing interorganizational cooperation in labour market reintegration: a case study
}

\author{
Christian Ståhl ${ }^{1}$ \\ ${ }^{1}$ National Centre for Work and Rehabilitation, Department of Medical and Health Sciences, Linköping \\ University, Linköping, Sweden \\ christian.stahl@liu.se
}

Running head: Implementing interorganizational cooperation in labour market reintegration 


\begin{abstract}
Introduction: To bring people with complex medical, social and vocational needs back to the labour market, interorganizational cooperation is often needed. Yet, studies of processes and strategies for achieving sustainable interorganizational cooperation are sparse. The aim of this study was to analyse the implementation processes of Swedish legislation on financial coordination, with specific focus on different strategies for and perspectives on implementing interorganizational cooperation. Methods: A multiple-case study was used, where two local associations for financial coordination were studied in order to elucidate and compare the development of cooperative work in two settings. The material, collected during a three-year period, consisted of documents, individual interviews with managers, and focus groups with officials.

Results: Two different implementation strategies were identified. In case 1, a linear strategy was used to implement cooperative projects, which led to difficulties in maintaining cooperative work forms due to a fragmented and time-limited implementation process. In case 2 , an interactive strategy was used, where managers and politicians were constantly involved in developing a central cooperation team that became a central part of a developing structure for interorganizational cooperation. An interactive cooperation strategy with long-term joint financing was here shown to be successful in overcoming organizational barriers to cooperation.

Conclusions: It is suggested that a strategy based on adaptation to local conditions, flexibility and constant evaluation is preferred for developing sustainable interorganizational cooperation when implementing policies or legislation affecting interorganizational relationships.
\end{abstract}

Keywords: Organizational case studies; sick-leave; unemployment; implementation 


\section{Introduction}

One of the most difficult challenges in vocational rehabilitation and labour market reintegration is how to manage people with complex needs. Some people are work-disabled due to combinations of medical, social and vocational problems, and studies in work disability prevention conclude that participatory, coordinated and tailored rehabilitation is effective for bringing people back to work [1-5].

However, the scope for holistic approaches to these issues is often limited, since it is common that the responsibility for the rehabilitation process is spread out over multiple actors, involving employers, health care, social insurance systems, and other [2, 4, 6]. While this differentiation may be considered a way to manage a complex environment [7], there is a risk that responsibility becomes fragmented, which may imply efficiency and quality problems [8]. Further, in attempts at interorganizational cooperation or integration in the rehabilitation field, organizational self-interest and low trust have been shown to threaten the development and sustainability of the cooperative initiatives [9-12].

In an attempt to resolve the problems of managing work-disabled people, legislation for financial coordination in the rehabilitation field has been introduced in Sweden. This legislation - FINSAM - came into force in 2004, allowing municipal social services, primary healthcare, the Social Insurance Agency and the Public Employment Service to form local associations for financial coordination, henceforth called Coordination Associations (CAs). The overall aim of these associations is to bring people back to the labour market, often after long-term absence due to various causes (such as unemployment, sickness or drug abuse). In the CAs, the participating organizations can engage in cooperative work forms on a local municipal level, with support from a joint budget, to target people that the organizations have not been able to manage in regular 
practice. Every CA has a local board and an office with a coordinator. The boards of the CAs consist of representatives from the four organizations, including officials from the two public authorities (the Social Insurance Agency and the Public Employment Service) and political representatives from the municipality and the county council. CA activities include, among other things, interdisciplinary teams to deal with sick-listings, projects for integration of immigrants, and interorganizational teams to manage labour market reintegration for the long-term unemployed. At the time of writing, there were 82 CAs, involving 197 of Sweden's 290 municipalities.

After some years, Coordination Associations have experienced different results, where a central challenge has been to implement new knowledge and working methods in regular practice. This study investigates the process perspective of implementing interorganizational cooperation.

\begin{abstract}
Aim
The aim of this study is to describe and analyse two cases of implementing interorganizational cooperation, where the implementation processes has had different results. In the study, theoretical propositions will be made (as specified in the theoretical framework) that will be investigated through the two cases. Central questions for the study are how implementation strategies developed, how central actors were involved in this process, and which elements in the strategies that affected the sustainability of the cooperation.
\end{abstract}

\title{
Implementation and learning: a theoretical framework
}

The concept of implementation may be defined and interpreted in numerous ways. This article will proceed from a rather fundamental definition of implementation as "a specific set of activities designed to put into practice an activity or program of known dimensions" [13, p. 5]. The literature on implementation comprises two traditions: research on policy implementation in public 
administration, and research on evidence-based practice (EBP) in human services [14]. There has been little interaction between these traditions, although both describe implementation processes. However, some elements are common to both, such as the need to identify an implementation object. In EBP studies, these are commonly guidelines or specific treatments in healthcare, while public administration research primarily focuses on the implementation of policies and political decisions. Hill and Hupe [15] conclude that it is difficult to draw conclusions about how the qualities of a policy influence the implementation outcome. In the end, the intention behind the policy is more important than the actual policy text, and certainly so in more open-ended policies; policy makers and implementers thus need to adapt their implementation strategies to the specific practical circumstances [15]. It is reasonable to assume that policies, being expressions of political will, are received and implemented differently in practice compared with treatments or guidelines that are based on research.

Apart from the implementation object, several contextual factors influence the implementation process, in EBP as well as in policy implementation. There are organizational factors such as organizational and managerial structures, as well as social, economic and political influences. In EBP research there is "good evidence for what does not work, reasonable evidence for what does work, and a clear lack of evidence in other areas" [13, p. 70]. What does not work is an overly simplistic strategy, such as focusing solely on information dissemination or training. Multi-level approaches, including an interactive implementation strategy, provide a better chance of successful implementation than a passive strategy for diffusion [16]. Also, the organization's capacity for absorbing new knowledge influences the outcome of the implementation [17]. Organizations, further, have established structures to ensure stability and continuity, which may resist the implementation of innovations [18]. An implementation process often takes a long time, and managerial support is important not only in the initial phase, but throughout the entire process in order for implementation to be sustainable $[13,19]$. Research on policy implementation has 
focused extensively on systemic and organizational levels, and a number of factors have been identified that affect implementation outcomes, including policy characteristics, interorganizational relationships, responses from those affected by the policy and policy context [15]. Many issues in policy implementation stem from cooperation problems between organizations, especially in social policies, due to the fact that citizens' needs are complex and public authorities are often too rigidly structured to meet these needs $[12,14]$. The purpose of the policy studied here is to overcome such issues through interorganizational cooperation projects.

It is common that an implementation object changes when it is adopted in a new context. Rogers [18] calls this re-invention, which tends to occur when the implemented innovation is complex; when it has a general scope with many possible applications; when it is aimed at solving a wide range of problems; and when it has to be adopted in different organizational structures. Reinvention, Rogers argues, is often perceived as desirable by the adopter and a higher degree of reinvention generally also results in faster and more sustainable adaptation. Rogers also distinguishes between three types of implementation agents: change agents, opinion leaders and gatekeepers [18]. The role of a change agent is to "facilitate the flow of innovations from a change agency to an audience of clients" $[18$, p. 368]. In this study, implementation agents could be the coordinators, who communicate and promote the cooperative ideas to the participating organizations, as well as managers and politicians.

Ellström [20] distinguishes two logics of learning that describe how innovations and ideas develop in organizations. In the logic of production, the focus lies on adaptive learning, standardization and implementation of explicit knowledge in practice. The logic of development, on the other hand, focuses on transforming implicit, tacit or practice-based knowledge into explicit work routines. In order for organizational learning to occur, both adaptive and developmental learning needs to take place. Implementation failures, Ellström argues, may be considered as failures from a managerial 
perspective, since learning is perceived as adapting explicit knowledge, while employees may have experienced successful changes in their work routines, relating to developmental learning. The logic of development focuses not on reducing variation, but on exploring diversity in thought and action. Barriers to such development may be subjective as well as organizational, cultural or structural [20].

\section{Theoretical propositions}

In this study, the primary implementation object is the FINSAM legislation, stating the regulatory framework for setting up interorganizational cooperation through CAs. This legislation is openended; only a framework for the authorities' work with interorganizational cooperation is defined, focusing on the formal responsibilities for the participating organizations. Adaptation to local conditions is therefore presumed, and the legislation does not state how cooperation is to be implemented. The legislation is thus likely to be subject for re-invention, as defined by Rogers [18].

Implementation is affected by the way an implementation object is re-invented in a local context, as well as by differences in the roles of implementation agents and the level of interaction between decision-makers (managers and politicians) and users (the officials participating in cooperative work). These factors, it is assumed, will influence the outcomes of the implementation processes, which lead to the following theoretical propositions:

- The cases will illustrate differences in implementation strategies with regard to how the FINSAM legislation was re-invented. A high level of adaptation will, according to theory, facilitate sustainable implementation.

- An implementation strategy characterized by interaction and openness to practical development is proposed to be preferred for achieving sustainable cooperation and to promote developmental interorganizational learning. 


\section{Methods}

A multiple-case study was used, which is appropriate when the subject of interest is complex and requires an in-depth approach. According to Yin [21], two-case studies are preferred over singlecase studies since it opens the possibility for analytic benefits, such as cross-case comparisons. This study has a two-tailed design, where cases with different outcomes were deliberately chosen to illustrate different approaches to the same implementation object. This allowed the study to investigate differences between the cases in relation to theory, i.e. a theoretical replication [21]. In these cases, cooperation teams in each CA were used as empirical starting points, and as examples of the results of the two implementation processes.

\section{Selection of cases}

Two interorganizational cooperation teams from two different CAs were chosen for inclusion since they represented two different outcomes; one team (Team 2, in CA 2) was sustainably implemented while the other (Team 1, in CA 1) was not. The specific teams were chosen to illustrate differences in how the two CAs approached implementation of the FINSAM legislation.

The term "team" was used by the CAs in describing the work forms, where a broad range of competencies used in an integrative way were supposed to be beneficial for the client in their rehabilitation. Both teams were groups of professionals with different competencies, involving medical staff, social workers, insurance officials and employment service officials. The teams were set to work with interorganizational cooperation to promote work and/or financial self-provision for people with complex social or medical problems that the participating authorities had failed to manage in regular practice. The two teams were similar in terms of purpose, target group, staffing, 
competencies and results (see Table 1). Both teams were set to work with a similar methodological approach, including joint assessments, coordinated medical, social and vocational rehabilitation, and a solution-based approach to individual needs.

(Table 1 about here)

It is worth noting that both teams were evaluated as being successful in financial terms for each participating authority, except for the Public Employment Service. The financial evaluation shows that Team 1 was slightly more successful than Team 2; however, Team 1 was shut down while Team 2 was continued.

\section{Material}

Multiple data sources and methods were used for the study. A combination of individual interviews, focus groups and documents was used to gather sufficient information about the cases. The range of material around the two selected cases is illustrated in Figure 1.

(Figure 1 about here)

Interviews were carried out at three points in time: at point one and three with board members (managers and politicians), and at point two as focus groups with street-level officials. Documents regarding the CAs in general and the specific teams in particular were collected and analysed. 
In the first set of interviews, carried out in 2007-2008, managers and/or politicians from all participating authorities in the two CAs were included, resulting in a total of 35 interviews. The respondents were either board members or representatives in a managerial group tied to the board. The respondents were asked questions about their role as representatives in the CA, including their perspective on implementation. In the follow-up interviews, carried out in 2009, the respondents were asked to reflect on the implementation process of the two teams as well as the CA as a whole, and on how implementation decisions were made. Eleven individual follow-up interviews were carried out, plus one interview with two respondents. The follow-up interviews also included the coordinators in each CA.

Focus groups with 15 street-level officials were carried out in 2009 for the purpose of studying interorganizational cooperation from the officials' perspective, and implementation issues were among the topics discussed. Two groups of officials, one in each CA, were recruited for participation in seven meetings per group. Each group consisted of both members from the teams and officials working outside the teams, and comprised social workers, social insurance officials, nurses, rehabilitation coordinators and employment service officials. The group in CA 1 contained eight officials, and the group in CA 2 seven officials. At the time of the interviews, Team 1 had recently been shut down. All interviews and focus groups were transcribed verbatim.

\section{Analysis}

The material was analysed in several steps. The first set of interviews with managers and politicians, and the focus groups with officials, were conducted with a broader aim than solely discussing implementation. This material was read for identification of parts relating to implementation of cooperative work, using qualitative content analysis [22]. From these readings, interview questions were derived for follow-up interviews with managers and politicians. Simultaneously, documents 
regarding the specific teams, the CAs in general and legislative text were retrieved and analysed with regard to information about implementation. When all material was gathered and organized case by case, the whole mass of text was studied and ordered chronologically to provide an understanding of the implementation processes in the two CAs [21]. The chronological order also facilitated a reading of the material as two separate narratives, incorporating how the implementation processes started and developed, and how the respondents talked about them [23].

The theoretical framework was developed simultaneously as the follow-up interviews were carried out, and as the analysis proceeded and the implementation strategies of the two CAs were becoming visible, a theoretical replication of the two cases was made. A theoretical replication involves comparing cases to what could be predicted outcomes relating to the theoretical propositions made [21]. In the analysis, this involved matching the patterns of the two cases to the theoretically expected outcomes.

\section{Results}

In this section, the two cases are presented as separate narratives. These case descriptions will thereafter, in the discussion, be analysed through a cross-case comparison and a theoretical replication.

\section{Case 1}

CA 1 was located in a medium-sized Swedish municipality (approx. 130,000 inhabitants) and was initiated in 2004.

After its initiation, CA 1 soon produced a general strategy for developing cooperative projects, where a key feature was to advertise to professionals working in the participating organizations to 
suggest ideas for work forms involving two organizations or more. The idea was to test ideas by providing financing for a limited time period, and thereafter evaluate the results and put those that were successful into regular practice. This strategy followed a thought line from idea to practice, as illustrated in Figure 2.

(Figure 2 about here)

During the first years, a number of projects were started; each focusing on different target groups (e.g. immigrants, women, long-term unemployed etc.). The cooperation team studied here was set up in 2006. In the contract for the team, the purpose is stated as

Offering a joint assessment and coordinated rehabilitation (medical, social, vocational and occupational) from the individuals' needs, with the goal to improve possibilities for employment. (Contract between CA and participating organizations, 2006)

Implementation of projects was among managers and politicians understood as transferring costs to the regular organizational budgets, and it was emphasized that implementing projects was necessary to provide long-term development.

Of course, otherwise there's a time limit for cooperation, and then there will never be any development. Then it turns into some sort of separate organization, a fifth authority, if you do everything with grants from [the CA]. Then the basic idea of it has been lost. (Social Insurance Agency manager, 2007)

The managers and the politicians in the CAs had previous experience of starting projects that had not been possible to continue for financial reasons, despite good results. Here it was hypothesized 
that the joint financing and involvement of politicians on the boards served to increase sustainability.

You get money, you start, you think it's good, but then to ... and these are political decisions ... to make them open their wallets and agree that this is good... Here, with the CA, there are politicians involved, to a certain extent, and I think it might be easier to implement. If not fully, then perhaps part of it. (Social Insurance Agency manager, 2007)

However, the influence of politicians were limited, according to the politicians themselves. Instead, managers were thought to have more influence over practice.

The managers in the authorities have more possibilities to influence their practices than us politicians do. We have no - I can't go in and tell a political committee what to do just because I'm a councillor. (Chairman, municipal politician, 2007)

Managers raised general concerns about cooperative work being outside their organizational budgets and production goals: engaging in long-term commitments was complicated by results taking time and uncertainty of outcomes. It was perceived as easier to work in short-term projects, and it was thus a conscious strategy not to initiate any permanent work forms with long-term joint financing. A consequence of this strategy was that for project implementation to be successful, work forms had to be maintained after the trial period, and the costs needed to be transferred to regular organizational budgets.

That's how we've reasoned. Then there will be projects that are... where the framework makes it more difficult to make it permanent. [...] When you permanently allocate resources from several authorities, it gets more complicated. I've been around long enough to have experienced trial work forms that 
have been evaluated with excellent results, but it still hasn't been possible to make them permanent. (Psychiatric manager, 2007)

An expected consequence of the strategy was that several work forms would not continue after the trial period, which also was the case. At the time of writing, more than 20 projects have been closed, among them the cooperative team in focus here, although a majority of the people involved politicians, managers and officials working in the team - had assumed that this team would continue. This assumption came from two sources: a positive evaluation of the team's results, and the feeling that the team was a central and necessary work form within the context of a CA. However, when the implementation discussion took place, managers from the Public Employment Service finally made the continuation of the team impossible by referring to organizational constraints in providing staff to the team.

\section{Officials' perspectives on closing the team}

On the street level, the need for cooperation was experienced in daily practice, and the work forms had by the officials been considered a relief from the constraints of organizational borders. They had experienced that the team facilitated communication between the authorities, as well as offering them individual and interorganizational learning opportunities. Hence, the officials expressed much disappointment over the closure of the team, and were critical of how the projectbased strategy had developed; good results and developed knowledge were not recognized and work forms not implemented.

What's the point of starting projects when they're not going to be followed up? They've evaluated some of them and said "this is amazing", and then shut them down. It's unbelievable. (Social worker, 2009) 
Failure to implement projects, as the officials perceived it, was primarily caused by managerial priorities, with managers not seeing the point of the cooperative work from their organizational perspective.

\section{Board members' perspectives on implementation and future strategies}

In interviews nine months after the team was shut down, managers and politicians were asked to look back on the implementation process and how they reasoned about strategies for future cooperation. Several respondents expressed considerable self-criticism, both regarding the implementation process for the teams, and regarding the strategy of organizing cooperation through short-term projects. In theory, many work forms initiated by the CAs could replace some of the existing routines and practices. In practice, the cooperative work forms came to fill gaps between the organizations, which implied that old routines persisted alongside the new. Thus, in order to implement a work form, something else would have had to be shut down, and since it was perceived easier to shut down a project than changing regular practice, many projects did not continue.

Several respondents suggested changing strategy toward developing knowledge and cooperation methods through long-term commitments. This, it was reasoned, could be done either by setting up permanent jointly financed cooperation structures, or by financing education and training within the current organizational structures.

There may be things that cannot be implemented. Personally, I'm beginning to think that ... well, if the starting point for the CAs is that people fall between authorities' responsibilities, that's where the work starts. [...] Then perhaps we need to take responsibility for a work form that targets this group or these needs that no authority covers. (County council politician, 2009) 
The project-based strategy called for multiple implementation processes of specific projects, focusing on project evaluations and managerial decisions. This process made it possible for managers to execute their power in not allowing projects to continue, and also opened up for external factors to influence the process. Timing thus became an issue.

This business of having trial work forms and then trying to implement them is not really a good way of working. It can turn out that it's just a matter of chance, it was chance, really. There wouldn't have been any problems if this discussion had come four or five months later. Then it [the team] would still be here. But at that specific time, there were staffing difficulties at the Public Employment Service. What we've learned is to work in a more long-term fashion, like [CA 2] does. They go in and take responsibility for this. They haven't even discussed implementation; they've taken for granted that this is a service that the CA should have at its core. (Coordinator, CA 1, 2009)

While it was clear in the first set of interviews that implementation of projects had not been discussed very thoroughly, the second set of interviews showed that the board members dealt with the consequences of this lack of communication. Project implementation became limited to a short time after a formal evaluation, where each participating authority was given the opportunity to say yes or no to the project. A shorter implementation process also put more focus on costs, formalities and temporary problems, which were used as a reason for withdrawing. The worries about previous experiences of implementation failure thus came true.

\section{Case 2}

CA 2 covered two smaller municipalities (approx. 49,000 inhabitants), where the CA was initiated in 2004 . 
Starting the CA was perceived as complicated, where the participating organizations had different ideas of how (and if) they were to implement the legislation. To overcome this, a communicationbased approach was used to develop a common standpoint.

It was very difficult to start. [...] The Social Insurance Agency had political orders to work with this, and finally, all the politicians got together in a room and said that "from now on, we speak with the same tongue, and we have to create this". And then it worked. (County council politician, 2009)

These discussions resulted in an overall implementation strategy for the CA, focusing on a cooperation team as a central work form. The team was to be continuously evaluated and adjusted according to current development needs (see Figure 3).

(Figure 3 about here)

The team was started in 2005 with the purpose to work with people

in need of coordinated rehabilitation focusing on the individual's possibilities of developing his/her work ability with employment as a goal. (CA operational plan, 2007)

From the beginning, the team was meant to be a long-term jointly financed work form, rather than a project. Surrounding the team, the CA financed services or measures directed towards specific target groups or needs identified by the participating organizations. The developing cooperation was designed from a process perspective, where the approach and resources were adjusted through continuous evaluations and discussions. 
Since the team was not considered a project, implementation of this specific work form was not extensively discussed among the board members in the CA. The team was considered a central part of the CA, and resources were allocated to it to make it sustainable.

I don't think we've had that discussion [about implementation] yet. It's possible that I haven't ...that we've talked about it, but we haven't raised it at the board meetings as far as I can remember. [...] I think we've rather ended up reasoning about where to put our resources, and mostly it's about the team, making that work. [...] After people have gone through the system in all kinds of dependent positions towards the government or the municipality, you come to something where you make a joint investment, and I think that's necessary. (Chairman, municipal politician, CA 2, 2007)

The team was considered as part of a whole, and implementation was therefore targeted at the CA as such rather than at the specific team. One of the politicians on the CA board reflected on how CA 2 differed from CA 1 in this respect:

They [CA 1] work more in projects, which you apply for, while we try to ... we've tried to see where the problems are and then to find things, like this team, that can fix them. So the team becomes an engine. As long as we have this CA, I think it will be the core and the engine.

(County council politician, 2009)

It was widely recognized among the board members that the team was a natural work form for the CA, and therefore a discussion about implementing it seemed redundant. The team was simply considered a symbol for the CA.

Well, we can have many things, but we have to have a coordination team, since it was considered a hub for the target group the CA is meant for. The CA is not there to finance development in regular practice or to finance shortcomings. In some way, the team is a symbol for the very point of the CA. 
It's to coordinate rehabilitation for people who need it. [...] So it was a core work form, so to speak. And there was no conflict around it in any way; it was something everyone said yes to.

(Coordinator, CA 2, 2009)

\section{Officials' perspective on working in the team}

The officials working in or with the team talked about it as an arena where the clients got their problems solved, as an end station.

As we say, [the team] is the end station, whether you're working or are retired afterwards, it's like: it ends here, because we'll get to the bottom of this. And that may imply that we need to assess them again, although it's already been done. (Social Insurance Agency official, 2009)

Since all participating organizations had their respective responsibilities, the team could function as a common arena for those cases where the organizational borders became a problem. The most prominent advantage of the team was the choice of methods available to officials, which made their work with clients flexible. A team member who had been employed at the Social Insurance Agency reflected over this difference:

But in [the team] it's, well I have the entire smorgasbord, plus the fact that I know all the rules in the back of my head. I know how long this person gets compensation, and then I can motivate them more. And as a team member, that's my role, to motivate and to fix. But as a Social Insurance Agency official, my role is more to inform and then it's up to the individual. (Social Insurance Agency official, 2009)

\section{Board members' experiences of cooperation projects}

The board members in CA 2 had experience of previous cooperative projects that had not been possible to continue. However, this team was generally perceived as being different from previous 
attempts at cooperation, because of its more permanent character. As a consequence, it was from the start perceived as a more sustainable structure. One of the important features seemed to be the decision not to incorporate it into the regular organizational structures, but to keep it as an external team organized and jointly financed through the CA. Relating to this, a Social Insurance Agency manager noted how the external form had been a precondition for maintaining it, since state authorities are too governed by rules to change their organizational practice. Keeping the team external was however not considered as being implementation, but a way of maintaining the team on a permanent basis.

They [the officials] use this a lot in practice, but we cannot do this on a regular basis. There's really no room in the legislation to have this work form, or to finance it. [...] Everyone agrees that this is needed, and then ... I talked to one of the politicians on the board and we discussed that perhaps some things are so good that they should continue, but that the CA, where we run things together, should finance it. Maybe it's too complicated to be implemented. (Social Insurance Agency manager, 2009)

It is worth noting how the team was perceived as a permanent exception from regular practice. The team could, through its permanent character, be established as a separate organization, functioning as a support structure for the participating organizations in managing cases where the organizational responsibility was unclear.

\section{Discussion}

In this section, a theoretical replication of the two cases will be made in relation to implementation theory, and in relation to previous studies of interorganizational cooperation. 


\section{Re-inventing the implementation object}

The first theoretical proposition was that the cases would illustrate differences in implementation strategies with regard to how the FINSAM legislation was re-invented, where a high level of reinvention would facilitate sustainable adaptation [18]. The re-invention of an implementation object may take many forms and may imply that an initial object (such as FINSAM in this case) will develop into different practices in different contexts.

In this regard, the two CAs had different approaches. CA 1 primarily re-invented FINSAM as a financial support system for developing projects, where each project subsequently needed to be implemented into regular practice if they were to continue. In CA 2, the implementation of FINSAM was made through a strategy aiming to establish the CA as a structure in the local political community, where the team became an arena for interorganizational cooperation. In this case, implementation was more concerned with the CA as a whole, rather than implementation of specific projects. Overall, this strategy was less formalized than the strategy of CA 1, and it used the CA more actively as an actor in organizing cooperation. In this way, the implementation process was given more time, and a specific ending point for the process was not stipulated. Further, there were fewer discussions of costs and formalities than in CA 1, since the managers and politicians were continuous engaged in developing the cooperation.

Rogers [18] argues that implementation is complete when an innovation has been institutionalized and made a part of the adopters' on-going operations, i.e. when the innovation loses its distinctive quality as being a new idea. According to this, CA 2 (and the corresponding team) could be considered sustainably implemented, since it had become a regular part of the participating organizations' operations in the specific local context, as a permanent exception from regular practice. In CA 1, where projects generally suffered from implementation failures, a consequence was that the CA as such was less successful in becoming institutionalized. 
Several studies has highlighted both the necessity of and the difficulties in engaging multiple actors in work disability prevention [3, 4, 10-12, 24]. For legislation on interorganizational cooperation to be successful in engaging the participating actors, sensitivity to each organization's perspective is necessary $[4,25]$, which suggests that such legislation need to be written and interpreted in a way that allow a flexible adaptation to the local context. The FINSAM legislation did not specify how the development of cooperation should be carried out, and it is reasonable to assume that implementation outcomes would be dependent on how the legislation was adapted to local contexts $[15,18]$.

While it is difficult to determine whether one re-invention of FINSAM meant a higher level of adaptation than the other, it may be said that CA 2 had a more interactive process than CA 1 . In CA 2, there was a flexible approach where managers, politicians and officials in the cooperation team developed the cooperation with sensitivity to emerging needs, reminiscent of the developmental learning process described by Ellström [20]. The project strategy of CA 1 allowed a multitude of projects to develop, but since the project strategy failed to make them sustainable, the development haltered. As a result, the project-based strategy of CA 1 increased the fragmentation of services, while CA 2 re-invented FINSAM into a common arena for cooperative work that, although it represented a new organization, had an integrative character and functioned as a support structure for the participating organizations in managing difficult cases [cf. 26].

\section{Differences in implementation strategies}

The second theoretical proposition concerned the difference in implementation strategies, where it was assumed that a strategy characterized by interaction and openness to practical development would be preferred $[13,16,17,19]$, thereby facilitating more sustainable cooperation and better 
prerequisites for developmental interorganizational learning [20]. In the two cases, there was a substantial difference in the overall strategy for implementing the CAs, with corresponding differences in the level of interaction between decision-makers (managers and politicians) and users (officials participating in cooperative work).

In CA 1, the project-based strategy proceeded from an idea of a linear development from testing work forms to implementing them into regular practice, where little interaction or flexibility was offered. As a consequence, each project had to go through an implementation process of its own, that was limited to a certain point in time when the trial period for the project was over. The failure to implement projects later made board members in CA 1 prone to change their attitude towards the use of the pooled budget, from only financing projects to allowing work forms to run on a longer term.

The more interactive strategy of CA 2 was developed through a communication-based approach after initial difficulties in reaching agreements on how to handle the legislation. This strategy, where managers and politicians were constantly involved in the process of developing cooperation, made it possible for managers to support locally developed ideas, although representing state authorities with bureaucratic regulations. On the other hand, the linear strategy in CA 1 resulted, in this case, in more gatekeeping on the part of managers, and organizational constraints were used as arguments for not implementing cooperative work forms. These differences serve as illustrations of conclusions from previous studies, that has emphasized managerial support throughout the process to make the implementation sustainable $[13,19]$. Thus, the strategy in CA 2 was more supportive for organizational learning by engaging managers and politicians in developmental as well as adaptive learning [20]. 
Both of the CAs in this study had coordinators to support the cooperative processes, and these acted as implementation agents in developing strategies for the CAs [18]. The board members (politicians and managers from the participating organizations) had the formal power to decide what the CAs would engage in, thereby acting as gatekeepers toward their organizations. Managers and politicians could also act as opinion leaders (promoting or opposing implementation) and change agents [18]. In collaboration between the coordinators and the board members, the two CAs interpreted the FINSAM legislation in different ways, where CA 2 to a higher extent than CA 1 allowed the ideas of individual board members and coordinators to influence the development of the cooperative work.

As has been noted, an organization's readiness to adopt innovations is important for implementation outcomes [17]. Highly formalized organizations (such as the bureaucratic state authorities in this study) are assumed to be more resistant to innovation, although implementation may be facilitated by a clear organizational structure [18]. Organizational and structural factors, such as national regulations, may also become barriers for organizational learning [20]. In this study, the same state authorities were represented in both CAs; however, since the implementation strategies differed, the outcomes were also different. In an interactive strategy, as in CA 2, the coordinator seems to have had better opportunities to act as an implementation agent [18] by involving and engaging managers, thereby reducing their gatekeeping opportunities.

Earlier studies of CAs or similar interorganizational cooperation attempts has demonstrated how organizational self-interest and low trust complicate cooperation [9-11], and a recent study concluded that the outcomes of such initiatives tend to focus on specific cooperation projects with limited influence on the participating organizations, since they tend to focus on top-down approaches rather than horizontal integration [26]. In the present study, it is suggested that CA 2 was more successful in creating a horizontal approach to interorganizational cooperation by not 
being limited to a number of project-based work forms; instead, in this local context the CA was established as a sustainable cooperation structure.

It could be argued from this study that there are better prospects for success in developing interorganizational cooperation and mutual organizational learning if an interactive implementation strategy is used, where the participating organizations are engaged on a longer term in specific cooperative structures. Therefore, the second theoretical proposition is supported.

\section{Methodological considerations}

The multiple-case method used in this article facilitated an analysis of implementation processes in different contexts. It may be argued that the conclusions about the different outcomes could have been attributed to factors other than those reported. The cases were considered similar enough to justify a comparison, and although many factors influence the outcomes of an implementation process, it is reasonable to assume that the conclusions derived from this study were significant, given the specific conditions and the organizational and political context described. Adding more cases could possibly have strenghened the study further in terms of the validity of the conclusions. The two-tailed selection of cases was thought to be purposeful for comparing different outcomes in similar settings [21], but conclusions should be interpreted with regard to the limitations of using only two cases.

Qualitative studies do not aim for generalization; rather, the aim is to provide transferable data [22]. The results of this study cannot be interpreted as describing generally valid factors behind implementation outcomes, but should be interpreted as specific to the reported cases. However, it is reasonable to assume that several aspects reported as influential here are relevant in many cases 
of implementation in an international context. The results from this study may thus be transferable to other similar contexts.

The trustworthiness of a qualitative study depends on four criteria: credibility, transferability, dependability, and confirmability [27]. Credibility can be understood as whether the reported findings from a study represent a credible conceptualization of the material; transferability is related to whether the results may be applicable to other contexts or projects; dependability is concerned with the overall quality of the research process from data collection to analysis; and confirmability is how well a study's findings are supported by the data collected. The results from the study have been presented and discussed at conferences with representatives from several CAs, which helped to improve the credibility and the confirmability of the findings. The dependability of the study is strengthened by discussions about the material with researchers in seminars and informal discussions.

\section{Conclusions}

This study illustrates how legislation on financial coordination in the rehabilitation field was interpreted and implemented differently in two local contexts. Of the two cases, one tried (and failed) to implement specific cooperative projects, while the other used a broader and more interactive strategy to establish and sustain interorganizational cooperation.

When implementing policies or legislation affecting interorganizational relationships, this study suggests that a strategy based on adaptation to local conditions, flexibility and constant evaluation is preferred for developing sustainable interorganizational cooperation. An interactive strategy, where the participating organizations are engaged for a longer term in specific cooperative 
structures, seem to provide coordinators, managers and politicians with better opportunities to act as implementation agents, as well as fewer gatekeeping opportunities. An interactive cooperation structure may thus facilitate the development of interorganizational cooperation and mutual organizational learning.

\section{References}

1. Bültmann U, Sherson D, Olsen J, Hansen CL, Lund T, Kilsgaard J. Coordinated and tailored work rehabilitation: A randomized controlled trial with economic evaluation undertaken with workers on sick leave due to musculoskeletal disorders. Journal of Occupational Rehabilitation. 2009;19(1):81-93.

2. Franche R-L, Baril R, Shaw W, Nicholas M, Loisel P. Workplace-Based Return-to-Work Interventions: Optimizing the Role of Stakeholders in Implementation and Research. Journal of Occupational Rehabilitation. 2005;15(4):525-42.

3. Kärrholm J, Ekholm K, Jakobsson B, Ekholm J, Bergroth A, Schüldt K. Effects on work resumption of a co-operation project in vocational rehabilitation. Systematic, multiprofessional, client-centered and solution-oriented co-operation. Disability and Rehabilitation. 2006;28(7):457-67.

4. Loisel P, Buchbinder R, Hazard R, Keller R, Scheel I, Tulder Mv, et al. Prevention of Work Disability Due to Musculoskeletal Disorders: The Challenge of Implementing Evidence. Journal of Occupational Rehabilitation. 2005;15(4):507-24.

5. Vermeulen SJ, Anema JR, Schellart AJM, Knol DL, van Mechelen W, van der Beek AJ. A Participatory Return-to-Work Intervention for Temporary Agency Workers and Unemployed Workers Sick-Listed Due to Musculoskeletal Disorders: Results of a Randomized Controlled Trial. Journal of Occupational Rehabilitation. 2011(Published online 19 February 2011). 
6. MacEachen E, Kosny A, Ferrier S, Chamber L. The "Toxic Dose" of System Problems: Why Some Injured Workers Don't Return to Work as Expected. Journal of Occupational Rehabilitation. 2010.

7. Lawrence PR, Lorsch JW. Differentiation and Integration in Complex Organizations. Administrative Science Quarterly. 1967;12(1):1-47.

8. Axelsson R, Axelsson SB. Integration and collaboration in public health - a conceptual framework. International Journal of Health Planning and Management. 2006;21:75-88.

9. Sandström U, Axelsson R, Lundborg CS. Inter-organisational integration for rehabilitation in Sweden - variation in views on long-term goals. International Journal of Integrated Care. 2004;4:1-11.

10. Wihlman U, Lundborg CS, Axelsson R. Barriers of inter-organisational integration in vocational rehabilitation. International Journal of Integrated Care. 2008;8:1-12.

11. Ståhl C, Svensson T, Petersson G, Ekberg K. A Matter of Trust? A Study of Coordination of Swedish Stakeholders in Return-to-Work. Journal of Occupational Rehabilitation. 2010;20(3):299-310.

12. Lindqvist R, Grape O. Vocational rehabilitation of the socially disadvantaged long-term sick: inter-organizational co-operation between welfare state agencies. Scandinavian Journal of Public Health. 1999;1:5-10.

13. Fixsen DL, Naoom SF, Blase KA, Friedman RM, Wallace F. Implementation Research: A Synthesis of the Literature. Tampa: University of South Florida; 2005.

14. Johansson S. Implementing evidence-based practices and programmes in the human services: lessons from research in public administration. Europen Journal of Social Work. 2010;13(1):109-25.

15. Hill M, Hupe P. Implementing Public Policy: Governance in Theory and in Practice. London: Sage; 2002. 
16. Nutley SM, Walter I, Davies HTO. Using evidence: How Research Can Inform Public Services. Bristol: The Policy Press; 2007.

17. Greenhalgh T, Robert G, Bate P, Kyriakidou O. Diffusion of Innovations in Service Organizations: Systematic Review and Recommendations. The Milbank Quarterly. 2004;82(4):581-629.

18. Rogers EM. Diffusion of innovations. 5 ed. New York: Free Press; 2003.

19. Panzano PC, Seffrin BA, Chaney-Jones S. The innovation diffusion and adoption research project (IDARP): Moving from the diffusion of research results to promoting the adoption of evidence-based innovations in the Ohio mental health system: Ohio Department of Mental Health, 2005, 16.

20. Ellström P-E. Practice-based innovation: a learning perspective. Journal of Workplace Learning. 2010;22(1/2):27-40.

21. Yin RK. Case Study Research : Design and Methods. London: Sage; 2009.

22. Patton MQ. Qualitative research and evaluation methods. 3 ed. London: Sage; 2002.

23. Czarniawska B. Narratives in Social Science Research. London: Sage; 2004.

24. Brunarski D, Shaw L, Doupe L. Moving toward virtual interdisciplinary teams and a multistakeholder approach in community-based return-to-work care. Work. 2008;30(3):329-36.

25. Friesen MN, Yassi A, Cooper J. Return-to-work: The importance of human interactions and organizational structures. Work. 2001;17(1):11-22.

26. Wihlman U, Lundborg CS, Holmström I, Axelsson R. Organizing vocational rehabilitation through interorganizational integration - a case study in Sweden. International Journal of Health Planning and Management. 2011;26:e169-e85.

27. Lincoln Y, Guba E. Naturalistic inquiry. Newbury Park: Sage; 1985. 


\begin{tabular}{|l|l|l|l|}
$\begin{array}{l}\mathbf{2 0 0 5 - 2 0 0 6} \\
\text { Contracts, } \\
\text { Operational } \\
\text { plans, legislative }\end{array}$ & $\begin{array}{l}\mathbf{2 0 0 7} \\
\text { Interviews with } \\
\text { text }\end{array}$ & $\begin{array}{l}\mathbf{2 0 0 8} \\
\text { managers and } \\
\text { politicians } \\
\text { (n=35) }\end{array}$ & Written \\
evaluations & & $\begin{array}{l}\mathbf{2 0 0 9} \\
\text { Focus groups } \\
\text { with officials } \\
\text { (n=15) } \\
\text { Interviews with } \\
\text { managers, } \\
\text { politicians and } \\
\text { coordinators } \\
\text { (n=13) }\end{array}$ \\
\hline
\end{tabular}

Figure 1: Timeline and material for the study.

\begin{tabular}{|l} 
Project application \\
Board \\
decision
\end{tabular}$\sum \begin{gathered}\text { Trial period } \\
(1-2 \text { yrs })\end{gathered} \sum$ Evaluation $\sum \begin{gathered}\text { Board } \\
\text { decision }\end{gathered} \sum \begin{gathered}\text { Implementation, or } \\
\text { project closure }\end{gathered}$

Figure 2: Implementation strategy of CA 1. 


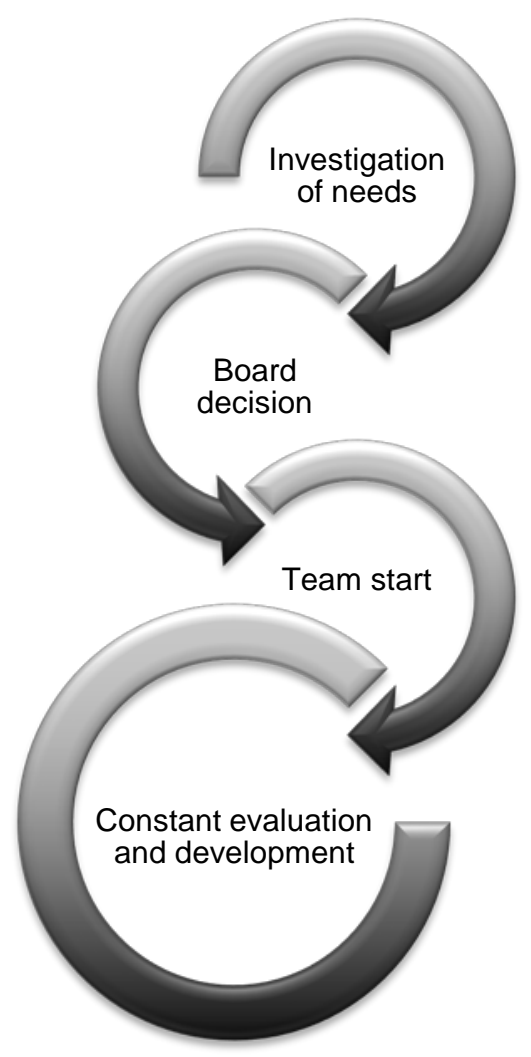

Figure 3: Implementation strategy of CA 2. 